\title{
Flora da Região de Xingó, Alagoas e Sergipe (Brasil): Turneraceae
}

\author{
Flora of Xingó Region, Alagoas and Sergipe (Brazil): Turneraceae
}

\author{
Lamarck Rocha ${ }^{1,5}$, Ramiro Gustavo Valera Camacho ${ }^{2}$, Margareth Ferreira de Sales ${ }^{3}$ \\ \& José Iranildo Miranda de Melo ${ }^{4}$
}

\begin{abstract}
Resumo
Este trabalho compreende o levantamento taxonômico da família Turneraceae para a Região de Xingó: Alagoas e Sergipe, Nordeste brasileiro. Foram encontradas nove espécies, distribuídas em dois gêneros: Piriqueta cistoides, P. guianensis, P. racemosa, Turnera calyptrocarpa, T. cearensis, T. chamaedrifolia, $T$. hermannioides, T. pumilea e T. subulata. O tratamento taxonômico inclui chave de identificação, descrições, ilustrações e comentários sobre os táxons.
\end{abstract}

Palavras-chave: Caatinga, florística, nordeste brasileiro, Piriqueta, Turnera.

\begin{abstract}
This work comprises the taxonomic survey of the family Turneraceae for the Xingó Region: states of Alagoas and Sergipe, Brazilian northeastern. Nine species distributed in two genera were found: Piriqueta cistoides, P. guianensis, P. racemosa, Turnera calyptrocarpa, T. cearensis, T. chamaedrifolia, T. hermannioides, $T$. pumilea and T. subulata. The taxonomic treatment includes an identification key, descriptions, illustrations and comments about the taxa.
\end{abstract}

Key words: Caatinga vegetation, floristics, Brazilian northeastern, Piriqueta, Turnera.

\section{Introdução}

Turneraceae é uma família predominantemente tropical com 12 gêneros e 229 espécies distribuídas na América e África (Arbo 2007). Turneraceae s.s., juntamente com Malesherbiaceae e Passifloraceae s.s., encontra-se circunscrita a Passifloraceae s.l., na ordem Malpighiales (APG IV 2016). Entretanto, estudos filogenéticos as sustentam como independentes (Thulin et al. 2012; Tokuoka 2012). Por esta razão, neste estudo considerou-se a circunscrição tradicional de Turneraceae, conforme Cronquist (1981).

No Brasil, Turneraceae está representada 158 espécies, distribuídas em dois gêneros: Piriqueta Aubl., com 39 espécies, e Turnera L., com 120 espécies (BFG 2015; Arbo 2015). Ocorrem em todas as regiões e domínios fitogeográficos, especialmente no Cerrado e Caatinga, os quais representam os principais centros de diversidade da família (Arbo \& Mazza 2011). Apesar de tratar-se de um grupo bem estudado do ponto de vista taxonômico (Arbo 1995a, 1997, 2000, 2005, 2008), ainda é pouco representado em floras locais, principalmente na região Nordeste do Brasil (Arbo 1995b; Agra et al. 2009; Rocha et al. 2012; Arbo 2013; Souza et al. 2013). O estudo de Arbo (2013) para o estado de Sergipe corresponde a uma importante contribuição para o conhecimento da flora da Região de Xingó, porém as espécies do estado de Alagoas têm permanecido desconhecidas, estando restritas a menções em listas florísticas (p. ex. Arbo 2006).

Através deste estudo, objetivou-se inventariar e caracterizar morfologicamente as espécies de

\footnotetext{
${ }^{1}$ Universidade Estadual de Feira de Santana, Prog. Pós-graduação em Botânica, Av. Universitária s/n, 44031-460, Feira de Santana, BA, Brasil.

${ }^{2}$ Universidade do Estado do Rio Grande do Norte, Prog. Pós-graduação em Ciências Naturais, Depto. Ciências Biológicas, Av. Prof. Antônio Campos s/n, 59633-010, Mossoró, RN, Brasil.

${ }^{3}$ Universidade Federal Rural de Pernambuco, Depto. Biologia, Prog. Pós-graduação em Botânica, R. Dom Manuel de Medeiros s/n, 52171-030, Recife, PE, Brasil.

${ }^{4}$ Universidade Estadual da Paraíba, Centro de Ciências Biológicas e da Saúde, Depto. Biologia, Av. das Baraúnas 351, 58429-500, Campina Grande, PB, Brasil.

${ }^{5}$ Autor para correspondência: lamarck_rocha@hotmail.com
} 
Turneraceae da Região de Xingó, abrangendo parte dos estados de Alagoas e Sergipe, além de prover chave de identificação, descrições, ilustrações e dados atualizados acerca da distribuição dos representantes desta família no domínio da Caatinga, dando continuidade ao projeto "Flora da Região de Xingó: Alagoas e Sergipe" (Melo et al. 2009a, b; Santos et al. 2009; Silva et al. 2010; Machado-Filho et al. 2012).

\section{Material e Métodos}

A Região de Xingó está situada no Nordeste brasileiro $\left(9^{\circ} 30^{\prime}-10^{\circ} 0^{\prime} \mathrm{S}, 37^{\circ} 30^{\prime}-38^{\circ} 0^{\prime} \mathrm{W}\right)$, na confluência dos estados de Alagoas, Bahia,
Pernambuco e Sergipe, com predominância da vegetação de caatinga [Savana Estépica Arborizada - IBGE (2012)]. A Região é cortada pelo rio São Francisco e se destaca como uma importante unidade geográfica e sociocultural no Brasil. A área estudada se localiza entre os estados de Alagoas (municípios de Olho d'Água do Casado, Pão de Açúcar e Piranhas) e Sergipe (municípios de Canindé do São Francisco, Nossa Senhora da Glória, Poço Redondo e Porto da Folha) (Fig. 1).

Foram analisadas as coleções dos herbários ASE, CTES, HUEFS, IPA, PEUFR, RB e UFP, além de espécimes coletados nos municípios

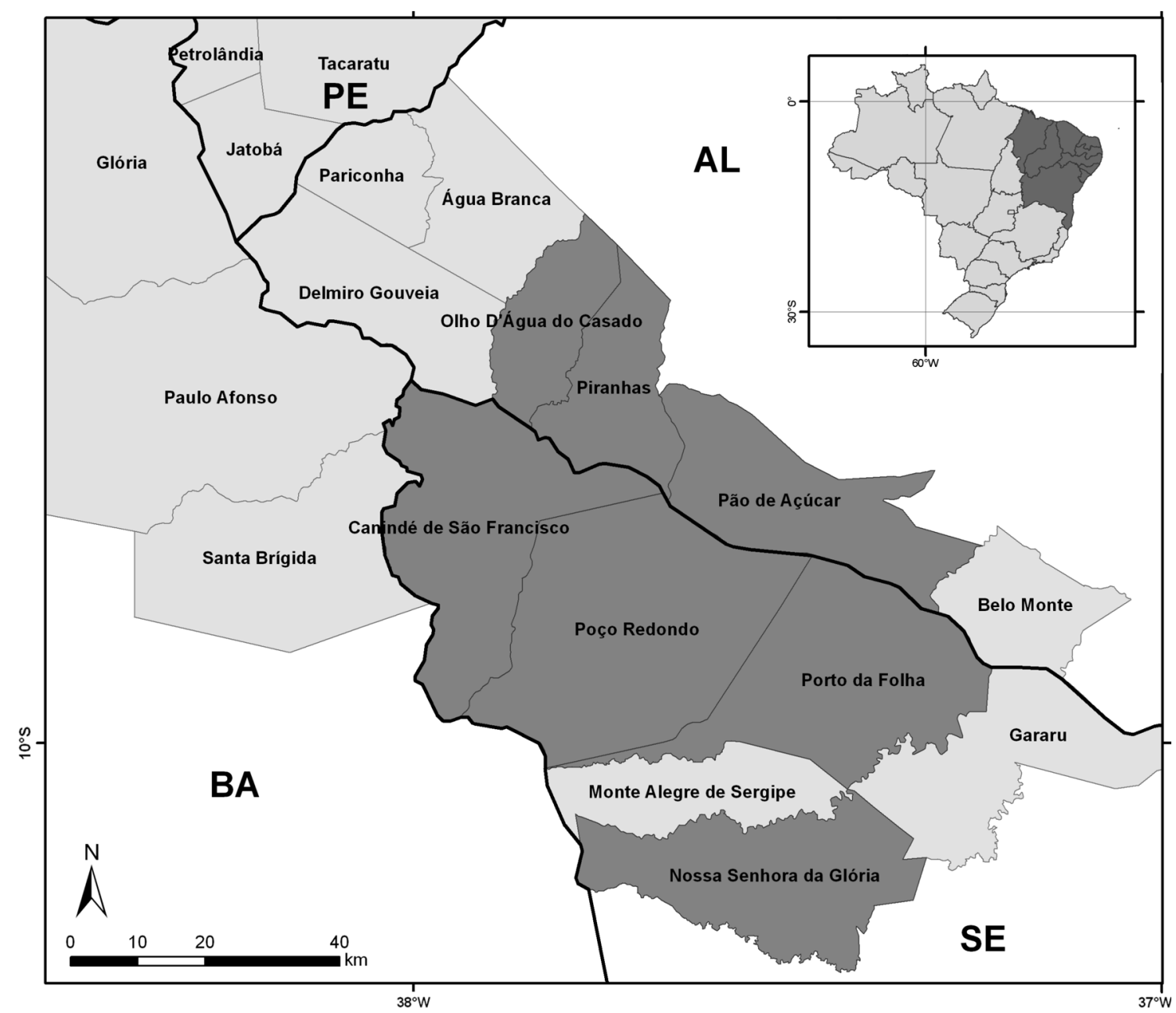

Figura 1 - Mapa de localização da Região de Xingó, evidenciando a área estudada em cinza-escuro (Canindé do São Francisco, Nossa Senhora da Glória, Olho d'Água do Casado, Pão de Açúcar, Piranhas, Poço Redondo e Porto da Folha). Fonte: IBGE 2012.

Figure 1 - Xingó Region location map, showing the study area in dark-grey (Canindé do São Francisco, Nossa Senhora da Glória, Olho d’Água do Casado, Pão de Açúcar, Piranhas, Poço Redondo and Porto da Folha). Font: IBGE 2012. 
supracitados, durante os anos de 1999 e 2002, através do projeto "Flora da Região de Xingó: Alagoas e Sergipe". As identificações foram realizadas com base em literatura especializada (Arbo 1995a, 1997, 2000, 2005, 2008). A terminologia morfológica se baseou em Radford et al. (1974) e Harris \& Harris (1994), enquanto os tipos de indumentos se fundamentaram em Payne (1978) e González \& Arbo (2004). As coordenadas dos municípios foram obtidas através da ferramenta GeoLoc (CRIA 2005). Os comentários referentes aos aspectos ecológicos e coloração das pétalas se basearam nas informações das etiquetas de herbário.

\section{Resultados e Discussão}

Para a Região de Xingó foram registradas nove espécies distribuídas em dois gêneros: Piriqueta, com três espécies, e Turnera, com seis espécies. De modo geral, são espécies de ampla distribuição no Nordeste brasileiro, ocorrendo principalmente em áreas de caatinga aberta, por vezes associadas a áreas antrópicas. Os caracteres que se mostraram mais úteis para a separação das espécies foram: a composição do indumento, coloração das pétalas e forma das bractéolas e sementes.
Tratamento Taxonômico

Turneraceae Kunth ex DC., Prodr. 3: 345 (1828), nom. cons.

Ervas a arbustos, anuais ou perenes. Folhas alternas, simples; geralmente com pares de nectários extraflorais basilaminares, circulares; venação broquidódroma. Estípulas 2, desenvolvidas ou rudimentares. Inflorescências cimosas, unifloras e axilares, raro formando um racemo terminal. Flores actinomorfas, bissexuais, hipóginas, homostilas ou heterostilas; pedúnculo livre ou adnato ao pecíolo (flor epifila); com ou sem pedicelo; brácteas presentes ou ausentes; bractéolas (profilos) 2, geralmente opostos, às vezes ausentes; sépalas 5 , porção basal gamossépala, prefloração quincuncial; pétalas 5, dialipétalas, alternissépalas, prefloração contorta; unha conata ao tubo calicino, constituindo um tubo floral; corona ausente ou presente e, neste caso, localizada na unha das pétalas e base das sépalas; estames 5, alternipétalos, livres entre si, por vezes, adnatos pelas margens ou porção basal ao tubo floral; anteras bitecas, dorsifixas, deiscência longitudinal, introrsas; ovário 3-carpelar, gamocarpelar, unilocular, placentação parietal; estiletes 3; estigmas penicelados. Cápsulas loculicidas, 3-valvares. Sementes com arilo desenvolvido.

\section{Chave para as espécies de Turneraceae da Região de Xingó, Alagoas e Sergipe (Brasil)}

1. Caules com tricomas tectores simples, estrelados, estrelados-porrectos, às vezes glandulares setiformes; flores com bractéolas rudimentares; corona presente.

2. Corola salmão; epicarpo granuloso, tricomas glandulares setiformes.......2. Piriqueta guianensis

2'. Corola amarela; epicarpo liso, tricomas tectores simples.

3. Flores reunidas em um racemo terminal; sementes lunadas 3. Piriqueta racemosa

3'. Flores solitárias; sementes obovoides 1. Piriqueta cistoides

1'. Caules com tricomas tectores simples ou estrelados, às vezes glandulares microcapitados, capitadoestipitados ou capitado-sésseis; flores com bractéolas desenvolvidas, 4-13 mm compr.; corona ausente.

4. Nectários extraflorais presentes.

5. Indumento com tricomas tectores simples e estrelados.

6. Subarbustos; flores com pedúnculo adnato ao pecíolo; filetes glabros; sementes oblongas, epiderme lisa 7. Turnera hermannioides

6'. Arbustos; flores com pedúnculo livre do pecíolo; filetes pilosos; sementes obovoides, epiderme papilosa. 5. Turnera cearensis

5'. Indumento apenas com tricomas tectores simples.

7. Caules tomentoso-hirsutos; flores homostilas; corola amarela, base amarelo-alaranjada; epicarpo liso; sementes lunadas, retículo proeminente 8. Turnera pumilea

7'. Caules estrigosos; flores heterostilas; corola creme, base castanho-escura; epicarpo verrucoso; sementes obovoides, retículo plano 9. Turnera subulata

4'. Nectários extraflorais ausentes. 
8. Tricomas glandulares capitado-estipitados; estípulas rudimentares; bractéolas subuladas; corola creme, base púrpura. 6. Turnera chamaedrifolia

8'. Tricomas glandulares capitado-sésseis; estípulas desenvolvidas, ca. $4 \mathrm{~mm}$ compr.; bractéolas espatuladas; corola branca, base amarelo-clara. 4. Turnera calyptrocarpa

1. Piriqueta cistoides (L.) Griseb., Fl. Brit. W.I.: 298. 1860.

Subarbustos ca. $1 \mathrm{~m}$ alt.; caules esparsohirsutos, tricomas tectores simples, estrelados e estrelado-porrectos, ferrugíneos, tricomas glandulares ausentes. Estípulas rudimentares. Folhas com pecíolo até $3 \mathrm{~mm}$ compr.; nectários ausentes; lâmina $0,5-3,3(-4) \times 0,1-1,2 \mathrm{~cm}$, cartácea, discolor, lanceolada, base cuneada, ápice agudo, margens denticuladas, discretamente revolutas; face adaxial hirsuta, face abaxial tomentoso-velutina. Flores axilares, solitárias, heterostilas; pedúnculo 1-2 cm compr., livre do pecíolo; brácteas e bractéolas ausentes; pedicelo 3-5 mm compr.; cálice 4-7 mm compr.; corola 9-10 mm compr., amarela; corona amarela; filetes glabros, base brevemente adnata ao tubo floral; anteras com ápice curvo; estiletes glabros. Cápsulas com epicarpo liso, esparsopiloso, tricomas tectores simples. Sementes ca. $1,5 \times 1 \mathrm{~mm}$, obovoides, discretamente curvas, reticuladas; epiderme lisa, retículo plano.

Iconografia: Arbo (1995a: 57a-f e 58a-r).

Material examinado: SERGIPE: Canindé de São Francisco, Monumento Natural Grota do Angico, 11.V.2010, fl. e fr., A.C.C. Silva 216 (ASE).

Material adicional examinado: SERGIPE: Neópolis, Pindoba, margens do rio São Francisco, 19.II.2014, fl. e fr., E. Melo et al. 12476 (HUEFS).

Ruderal, amplamente distribuída na América (Arbo 1995a). Ocorre na maioria dos estados brasileiros (BFG 2015). São reconhecidas duas subespécies: P. cistoides subsp. cistoides (L.) Griseb. e P. cistoides subsp. caroliniana (Walt.) Arbo (Arbo 1995), apenas esta última ocorre na Região de Xingó. Foi encontrada na caatinga, em afloramentos rochosos, florescendo e frutificando em maio.

Piriqueta cistoides subsp. caroliniana pode ser reconhecida pelas flores heterostilas, axilares, solitárias, corola amarela e sementes discretamente curvas com retículo plano; a subespécie típica diferencia-se principalmente pelas flores homostilas e hábito herbáceo (Arbo 1995a). Assemelha-se a P. racemosa, a qual se diferencia pelas flores reunidas em racemo terminal e sementes lunadas.
2. Piriqueta guianensis N.E. Br., Trans. Linn. Soc. London, Bot. ser. 2, 6: 30. 1901.

Fig. 2a-c

Subarbustos 0,4-1 m alt.; caules esparsopilosos a tomentosos, tricomas tectores estreladoporrectos ferrugíneos e glandulares setiformes. Estípulas rudimentares. Folhas com pecíolo 0,5-6 mm compr.; nectários ausentes; lâmina 1-4 × 0,4-0,7 cm, menor no ápice dos ramos, cartácea, discolor, ovada, elíptica a lanceolada, base atenuada, ápice agudo a obtuso, margens serreado-crenadas, revolutas; face adaxial tomentosa, face abaxial tomentoso-velutina. Flores axilares, solitárias, heterostilas; pedúnculo 1,4-2,4 cm compr., livre do pecíolo; brácteas ausentes; bractéolas rudimentares; pedicelo 4-8 mm compr.; cálice 1-1,3 cm compr.; corola 1,5-2 cm compr., salmão, base amarela; corona roxa; filetes glabros, base brevemente adnata ao tubo floral; anteras com ápice curvo; estiletes glabros. Cápsulas com epicarpo granuloso, hirsuto, tricomas glandulares setiformes de base hialina. Sementes ca. $2 \times 0,8-1 \mathrm{~mm}$, estreito-obovoides, discretamente curvas, reticuladas; epiderme lisa, retículo plano.

Iconografia: Rocha \& Moreira (2014: fotos 13-14); Arbo (1995a: 52f-i).

Material examinado selecionado: SERGIPE: Canindé do São Francisco, fazenda Jerimum, 24.III.1999, fl. e fr., R.A. Silva \& D. Moura 916 (UFP); Fazenda Baixa Verde, 2.VI.1999, fl. e fr., D. Moura 304 (UFP); Fazenda Poço Verde, 3.III.2000, fl. e fr., D. Moura \& R.A. Silva 1085 (PEUFR, UFP).

Apresenta distribuição disjunta, sendo registrada na Guiana, na região Norte (Roraima) e na maioria dos estados do Nordeste brasileiro (BFG 2015), onde ocorre ruderalmente. São reconhecidas duas subespécies: Piriqueta guianensis subsp. guianensis e P. guianensis subsp. elongata (Urb. \& Rolfe) Arbo (Arbo 1995a); apenas esta última ocorre na Região de Xingó. Foi encontrada na caatinga, tabuleiros, em áreas abertas, às vezes antrópicas, crescendo em substratos argilosos e arenosos; floresce e frutifica praticamente durante o ano todo.

Piriqueta guianensis subsp. elongata é endêmica do Nordeste brasileiro, podendo ser 


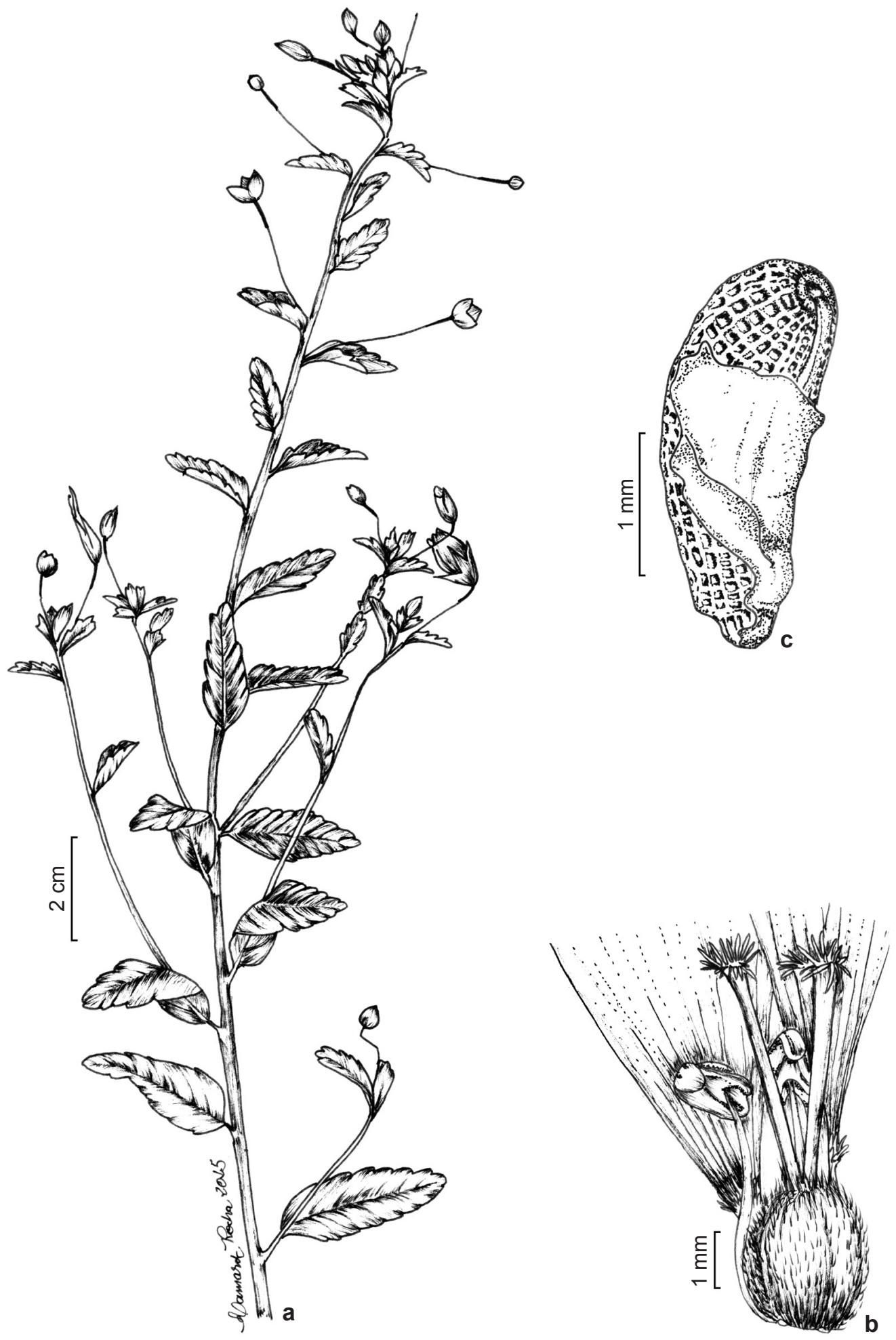

Figura 2 -a-c. Piriqueta guianensis - a. ramo reprodutivo; b. parte de uma flor longistila, com duas pétalas seccionadas, corona, 2 estames e gineceu; c. semente (Moura 1085).

Figure 2 - a-c. Piriqueta guianensis - a. reproductive branch; b. part of a long-styled flower, with 2 sectioned petals, corona, 2 stamens and gynoecium; c. seed (Moura 1085). 
reconhecida principalmente pela corola salmão, com base amarela, e pela corona roxa, além da presença de tricomas glandulares setiformes de base hialina no epicarpo. A subespécie típica ocorre apenas nas Guianas e Roraima, diferenciando-se pelos estiletes pilosos (vs. glabros), sementes de 1,5-1,8 mm compr. (vs. 1,9-2,3 mm compr.) e nervuras secundárias com ângulo de divergência de $22-45^{\circ}$ (vs. 18-30) (Arbo 1995a).

3. Piriqueta racemosa (Jacq.) Sweet, Hort. Brit.: 1: 154.1826.

Ervas 20-30 cm alt.; caules hirsutos, tricomas tectores simples, estrelados e estrelado-porrectos ferrugíneos, tricomas glandulares ausentes. Estípulas rudimentares. Folhas com pecíolo até $1 \mathrm{~cm}$ compr.; nectários ausentes; lâmina 2,2-5,2 $\times 0,7-2,5 \mathrm{~cm}$, reduzida na porção terminal dos ramos, cartácea, discretamente discolor, ovada, base cuneada, ápice agudo, margens serreadocrenadas, discretamente revolutas; face adaxial denso-pilosa, face abaxial tomentoso-velutina. Flores axilares, reunidas em um racemo terminal, heterostilas; pedúnculo $0,7-2(-3,3) \mathrm{cm}$ compr., livre do pecíolo; brácteas e bractéolas ausentes; pedicelo 2-5 mm compr.; cálice 4-5(-7) mm compr.; corola ca. $9 \mathrm{~mm}$ compr., amarela, base amarelo-escura; corona amarelo-escura; filetes glabros, base brevemente adnata ao tubo floral; anteras com ápice curvo; estiletes glabros. Cápsulas com epicarpo liso, esparso-hirsuto, tricomas tectores simples. Sementes ca. 1,7 × $1 \mathrm{~mm}$, lunadas, reticuladas; epiderme papilosa, retículo proeminente.

Iconografia: Rocha \& Moreira (2014: fotos 16-17); Arbo (1995a: 59a-f).

Material examinado selecionado: ALAGOAS: Piranhas, Fazenda Baixa da Légua, 10.VIII.1999, fl. e fr., D. Moura \& R.A. Silva 554 (UFP). SERGIPE: Canindé do São Francisco, Fazenda Jaburu, 10.XI.1999, fl. e fr., R.A. Silva \& D. Moura 1225 (UFP); Poço Redondo, Serra da Guia, 21.IX.2009, fl. e fr., W.J. Machado \& J.B. Jesus 25 (ASE).

Ruderal, ocorre principalmente na América do Sul e Velho Mundo (Arbo 1995a). No Brasil, ocorre na maioria dos estados do Nordeste (exceto Maranhão) e Sudeste (Espírito Santo, Minas Gerais e Rio de Janeiro) (BFG 2015). Na Região de Xingó, foi encontrada na caatinga em áreas abertas, antrópicas; floresce e frutifica durante o ano todo.

Pode ser reconhecida pelas flores reunidas em racemos terminais e sementes lunadas com retículo proeminente. Assemelha-se a Piriqueta cistoides, a qual se diferencia pelas flores solitárias e sementes discretamente curvas com retículo plano.
4. Turnera calyptrocarpa Urb., Jahrb. Königl. Bot. Gart. Berlin 2: 128. 1883.

Subarbustos ca. $70 \mathrm{~cm}$ alt.; caules esparsopilosos, tricomas tectores simples e glandulares capitado-sésseis. Estípulas ca. 4 mm compr., subuladas. Folhas com pecíolo 1-5 mm compr.; nectários ausentes; lâmina $0,7-2 \times 0,4-0,8 \mathrm{~cm}$, cartácea, discretamente discolor, obovada, base cuneada, ápice obtuso, margens serreado-crenadas, revolutas; face adaxial esparso-pilosa, face abaxial pilosa. Flores axilares, solitárias, heterostilas; pedúnculo ca. $2 \mathrm{~mm}$ compr., livre do pecíolo; brácteas ausentes; bractéolas 4-5 mm compr., espatuladas; pedicelo ausente; cálice 6-8 $\mathrm{mm}$ compr.; corola 0,8-1 cm compr., branca, base amarelo-clara; corona ausente; filetes pilosos, base brevemente adnata ao tubo floral; anteras com ápice reto; estiletes esparso-pilosos na porção média. Cápsulas com epicarpo tenuamente granuloso, piloso, tricomas tectores simples. Sementes ca. $2 \times 1 \mathrm{~mm}$, obovoides, discretamente curvas, reticuladas; epiderme papilosa, retículo plano.

Iconografia: Rocha \& Moreira (2014: foto 34); Arbo (2000: 16a-h).

Material examinado selecionado: ALAGOAS: Olho D’Água do Casado, Fazenda Capelinha, 21.I.2002, fl. e fr., L.M. Cordeiro 667 (PEUFR). SERGIPE: Canindé do São Francisco, Fazenda Brejo, 31.VIII.2000, fl. e fr., R.A. Silva \& D. Moura 1756 (RB); Poço Redondo, Fazenda Charco, 2.IV.2008, fl. e fr., J.E. Nascimento-Junior \& D.S. Melo 312 (ASE); Nossa Senhora da Glória, povoado Boa Sorte, 27.VII.2011, fl. e fr., G.M.A. Matos 20 (ASE).

Ocorre apenas no Brasil, no Nordeste (exceto Maranhão) e Sudeste (Minas Gerais) (BFG 2015). Na Região de Xingó, foi encontrada na caatinga, em áreas antrópicas como trilhas ou pasto, crescendo sobre substratos argilosos ou pedregosos; floresce e frutifica praticamente durante o ano todo.

Pode ser reconhecida pelas flores com bractéolas espatuladas, corola branca com base amarelo-clara, além das folhas às vezes congestas, formando braquiblastos no ápice dos ramos. Assemelha-se a Turnera diffusa Willd. ex Schult., não ocorrente na área estudada, a qual se diferencia pelas flores com bractéolas subuladas e corola amarela.

5. Turnera cearensis Urb., Jahrb. Königl. Bot. Gart. Berlin 2: 100. 1883.

Arbustos 50-70 cm alt.; caules pilosos a tomentosos, tricomas tectores simples e estrelados, tricomas glandulares ausentes. Estípulas 1-2 mm compr., subuladas. Folhas com pecíolo 1,1-10 
mm compr.; 1-2 pares de nectários, basilaminares; lâmina 2,5-5,4 × 0,9-1,2 cm, cartácea, discolor, ovada, raro obovada, base cuneada, ápice agudo, margens crenadas, discretamente revolutas; face adaxial pilosa a tomentosa, face abaxial tomentosovelutina. Flores axilares, solitárias, heterostilas; pedúnculo ca. $4 \mathrm{~mm}$ compr., livre do pecíolo; brácteas ausentes; bractéolas 5-9 mm compr., linear-lanceoladas; pedicelo ausente; cálice 9,5-10 mm compr.; corola ca. 1,1 cm compr., amarela; corona ausente; filetes pilosos, margens ca. 3 $\mathrm{mm}$ adnatas à unha das pétalas, formando sacos nectaríferos entre cada estame e a sépala oposta; anteras com ápice reto; estiletes pilosos. Cápsulas com epicarpo granuloso, piloso a tomentoso, tricomas tectores simples. Sementes ca. $3 \times 1$ $\mathrm{mm}$, obovoides, discretamente curvas, estriadoreticuladas; epiderme papilosa, retículo plano.

Iconografia: Rocha \& Moreira (2014: fotos 38-40); Arbo (2005: 12a-j).

Material examinado selecionado: ALAGOAS: Olho d'Água do Casado, Fazenda Capelinha, 21.I.2002, fr., L.M. Cordeiro et al. 670 (PEUFR). SERGIPE: Canindé do São Francisco, 29.XI.2000, fl. e fr., L.M. Cordeiro et al. 286 (PEUFR); Poço Redondo, Serra da Guia, trilha acima do olho d'água, 26.IV.2009, fl. e fr., A.P. Prata et al. 1651 (ASE).

Ocorre apenas no Brasil, no Nordeste e Sudeste (Minas Gerais) (BFG 2015). Na Região de Xingó, foi encontrada na caatinga e brejos de altitude; floresce e frutifica durante o ano todo.

Pode ser reconhecida pelas flores solitárias, pedúnculos desenvolvidos, livres do pecíolo, bractéolas linear-lanceoladas e corola amarela. Assemelha-se a Turnera blanchetiana Urb., não ocorrente na área estudada, a qual se diferencia pelas flores bracteadas, dispostas em capítulos.

6. Turnera chamaedrifolia Cambess., in Saint-Hil., Juss.\& Cambess., Fl. Bras. Merid. 2: 221. 1829.

Subarbustos 0,3-2,5 m alt.; caules pilosos, tricomas tectores simples e glandulares capitadoestipitados. Estípulas rudimentares. Folhas com pecíolo 2-9 mm compr.; nectários ausentes; lâmina 0,9-3 × 0,5-1,6 cm, cartácea, discretamente discolor, ovada a obovada, base atenuada, ápice agudo, margens serreado-crenadas, discretamente revolutas; face adaxial esparso-pilosa, face abaxial pilosa. Flores axilares, solitárias, heterostilas; pedúnculo 4-9 mm compr.; livre do pecíolo, às vezes brevemente adnato; brácteas ausentes; bractéolas 6-10 mm compr., subuladas; pedicelo ausente; cálice 8-15 mm compr.; corola 1,3-1,5 cm compr., creme, base púrpura; corona ausente; filetes glabros, base brevemente adnata ao tubo floral; anteras com ápice curvo; estiletes glabros. Cápsulas com epicarpo verrucoso, tomentosohirsuto, tricomas tectores simples. Sementes ca. 2 $\times 1 \mathrm{~mm}$, obovoides, retas ou curvas, reticuladas; epiderme lisa, retículo ligeiramente proeminente.

Iconografia: Rocha \& Moreira (2014: fotos 41-42) Arbo (2000: 20a-f).

Material examinado selecionado: ALAGOAS: Olho d'Água do Casado, 22.XI.1999, fl. e fr., R.A. Silva \& D. Moura 1315 (PEUFR); Piranhas, área urbana, 20.IV.1999, fr., D. Moura \& M. Sales 77 (PEUFR). SERGIPE: Canindé do São Francisco, Fazenda Xingó, $3 \mathrm{~km}$ da divisa com a Bahia, 25.IV.2001, fl. e fr., R.M. Harley et al. 54307 (CTES, HUEFS); Poço Redondo, Serra da Guia, 17.I.2010, fl. e fr., W.J. Machado et al. 146 (ASE); Porto da Folha, povoado Lagoa Grande, Fazenda São Pedro, 18.X.2011, fl. e fr., D.G. Oliveira et al. 330 (ASE).

Ruderal, ocorre apenas no Brasil, no Nordeste (exceto Maranhão) e Sudeste (Minas Gerais e Rio de Janeiro) (BFG 2015). Na Região de Xingó, foi encontrada na caatinga, em áreas abertas e antropizadas; floresce e frutifica praticamente durante o ano todo.

Pode ser reconhecida pelo indumento com tricomas glandulares capitado-estipitados, flores com pedúnculos livres do pecíolo e corola creme com base púrpura. Assemelha-se a Turnera calyptrocarpa, a qual se diferencia pelas flores com bractéolas espatuladas e corola branca com base amarelo-clara. Também é similar a Turnera asymmetrica Arbo, endêmica da Bahia, a qual se diferencia principalmente pelo indumento com tricomas capitado-sésseis e flores com bractéolas ovadas e assimétricas (Arbo 2000).

7. Turnera hermannioides Cambess., in Saint-Hil., Juss. \& Cambess., F1. Bras. Merid. 2: 218. 1829.

Subarbustos ca. $70 \mathrm{~cm}$ alt.; caules tomentosos, tricomas tectores simples e estrelados, tricomas glandulares ausentes. Estípulas rudimentares. Folhas com pecíolo 1-3 mm compr.; nectários 2, basilaminares; lâmina 0,7-3,5 ×0,5-2 cm, cartácea, discretamente discolor, ovada a obovada, base atenuada, ápice agudo, margens serreado-crenadas, planas; face adaxial denso-pilosa, face abaxial tomentosa. Flores axilares, solitárias, heterostilas; pedúnculo 3-4 mm compr., adnato ao pecíolo (flores epifilas); brácteas ausentes; bractéolas 5-7 mm compr., subuladas; pedicelo ausente; cálice ca. $7 \mathrm{~mm}$ compr.; corola ca. 1,5 cm compr., amarelo-clara, raro creme, base às vezes amareloescura; corona ausente; filetes glabros, margens 
ca. $3 \mathrm{~mm}$ adnatas à unha das pétalas, formando sacos nectaríferos entre cada estame e a sépala oposta; anteras com ápice reto; estiletes pilosos. Cápsulas com epicarpo verrucoso, denso-hirsuto, tricomas tectores simples. Sementes 2,3-2,5 $\times$ ca. $1 \mathrm{~mm}$, oblongas, discretamente curvas, reticuladas; epiderme lisa, retículo plano.

Iconografia: Rocha \& Moreira (2014: fotos 52-53); Arbo (2005: 28a-g).

Material examinado: SERGIPE: Canindé do São Francisco, 24.VIII.1999, fl. e fr., D. Moura 639 (PEUFR). Material adicional examinado: BAHIA: Licínio de Almeida, subida para área do Saco da Onça, 1444'44"S, 42³4'23'W, 932 m, 5.IV.2013, fl. e fr., L. Rocha et al. 399 (ALCB, HUEFS).

Ocorre apenas no Brasil, nas regiões CentroOeste (Goiás), Nordeste (Bahia, Piauí, Pernambuco, Sergipe), Norte (Tocantins) e Sudeste (Espírito Santo e Minas Gerais) (BFG 2015). Na Região de Xingó, foi encontrada na caatinga, com flores e frutos em agosto.

Pode ser reconhecida pelo indumento com tricomas estrelados e sementes oblongas. Assemelha-se a Turnera scabra Millsp., não ocorrente na área estudada, a qual se diferencia pelo indumento apenas com tricomas simples e sementes estreito-obovoides, claviformes.

8. Turnera pumilea L., Syst. Nat. ed. 10, 2: 965. 1759.

Fig. 3a,c

Ervas 10-15 cm alt.; caules tomentosohirsutos, tricomas tectores simples, tricomas glandulares ausentes. Estípulas rudimentares. Folhas com pecíolo até $4 \mathrm{~mm}$ compr.; 1 par de nectários, basilaminares; lâmina 1,5-2 × 0,8-1 $\mathrm{cm}$, cartácea, discretamente discolor, ovada, base cuneada, ápice agudo, margens crenadas a serreado-crenadas, planas; face adaxial esparsopilosa, face abaxial hirsuta a denso-hirsuta. Flores axilares, solitárias, homostilas; pedúnculo 3-4 $\mathrm{mm}$ compr., adnato ao pecíolo (flores epifilas); brácteas ausentes; bractéolas 5,5-7 mm compr., lineares; pedicelo ausente; cálice ca. $5 \mathrm{~mm}$ compr.; corola ca. $7 \mathrm{~mm}$ compr., amarela, base amareloalaranjada; corona ausente; filetes glabros, base brevemente adnata ao tubo floral; anteras com ápice reto; estiletes glabros. Cápsulas com epicarpo liso, base glabra, ápice hirsuto a denso-hirsuto, tricomas tectores simples. Sementes ca. $2 \times 1$ $\mathrm{mm}$, lunadas, reticuladas; epiderme ornamentada, retículo proeminente.

Iconografia: Rocha \& Moreira (2014: fotos 86-88); Arbo (2008: 66-67).
Material examinado: SERGIPE: Canindé do São Francisco, 19.III.1999, bt., fr., R.A. Silva 895 (PEUFR). Material adicional examinado: BAHIA: Morro do Chapéu, BA-052, a $18 \mathrm{~km}$ de Morro do Chapéu, $11^{\circ} 55^{\prime}$ S, $41^{\circ} 15^{\prime} \mathrm{W}, 28 . I .2013$, fl., L. Rocha \& B.S. Gregório 383 (HUEFS).

Ruderal, amplamente distribuída, principalmente na América Central e do Sul (Arbo 2008). No Brasil, ocorre em quase todas as regiões (exceto Sul) (BFG 2015). São reconhecidas duas variedades: T. pumilea var. pumilea e T. pumilea var. piauhyensis Urb., apenas a primeira ocorre na Região de Xingó. Foi encontrada na caatinga, com botões e frutos em março.

Turnera pumilea var. pumilea pode ser reconhecida pelas folhas geralmente congestas em rosetas apicais, flores homostilas, cápsulas hirsutas a denso-hirsutas apenas no ápice, além das sementes lunadas, com epiderme ornamentada apresentando cera epicuticular filiforme, conferindo aspecto piloso à superfície. T. pumilea var. piauhyensis se diferencia principalmente pelas flores heterostilas (Arbo 2008). Quando estéril, pode ser confundida com indivíduos jovens de T. subulata, a qual se diferencia pelo caule com indumento estrigoso e folhas regularmente dispostas nos ramos.

9. Turnera subulata Sm., in Rees, Cycl. 36(2): 441. 1817.

Fig. $3 b$

Subarbustos 15-70 cm alt.; caules estrigosos, tricomas tectores simples e glandulares microcapitados. Estípulas rudimentares. Folhas com pecíolo 0,3-1,5 cm compr.; 1 par de nectários, basilaminares; lâmina 1-12,1 × 0,3-5 $\mathrm{cm}$, cartácea, discretamente discolor, ovada, obovada a lanceolada, base atenuada a cuneada, ápice agudo a obtuso, margens serreadas a serreado-crenadas, planas; face adaxial estrigosa, face abaxial denso-estrigosa. Flores axilares, solitárias, heterostilas; pedúnculo 2-4 mm compr., adnato ao pecíolo (flores epífilas); bractéolas 9-13 mm compr., subuladas a lanceoladas; pedicelo ausente; cálice 7-2,9 mm compr.; corola 3,5-3,8 cm compr., creme, base castanho-escura; corona ausente; filetes glabros, margens ca. 1,5 $\mathrm{mm}$ adnatas à unha das pétalas, formando sacos nectaríferos entre cada estame e a sépala oposta; anteras com ápice reto; estiletes glabros. Cápsulas com epicarpo verrucoso, esparso-piloso, tricomas tectores simples. Sementes $2-3 \times$ ca. $1 \mathrm{~mm}$, obovoides, discretamente curvas, reticuladas; epiderme lisa, retículo ligeiramente proeminente. Iconografia: Rocha \& Moreira (2014: fotos 93-95); Arbo (2005: 56f-j). 


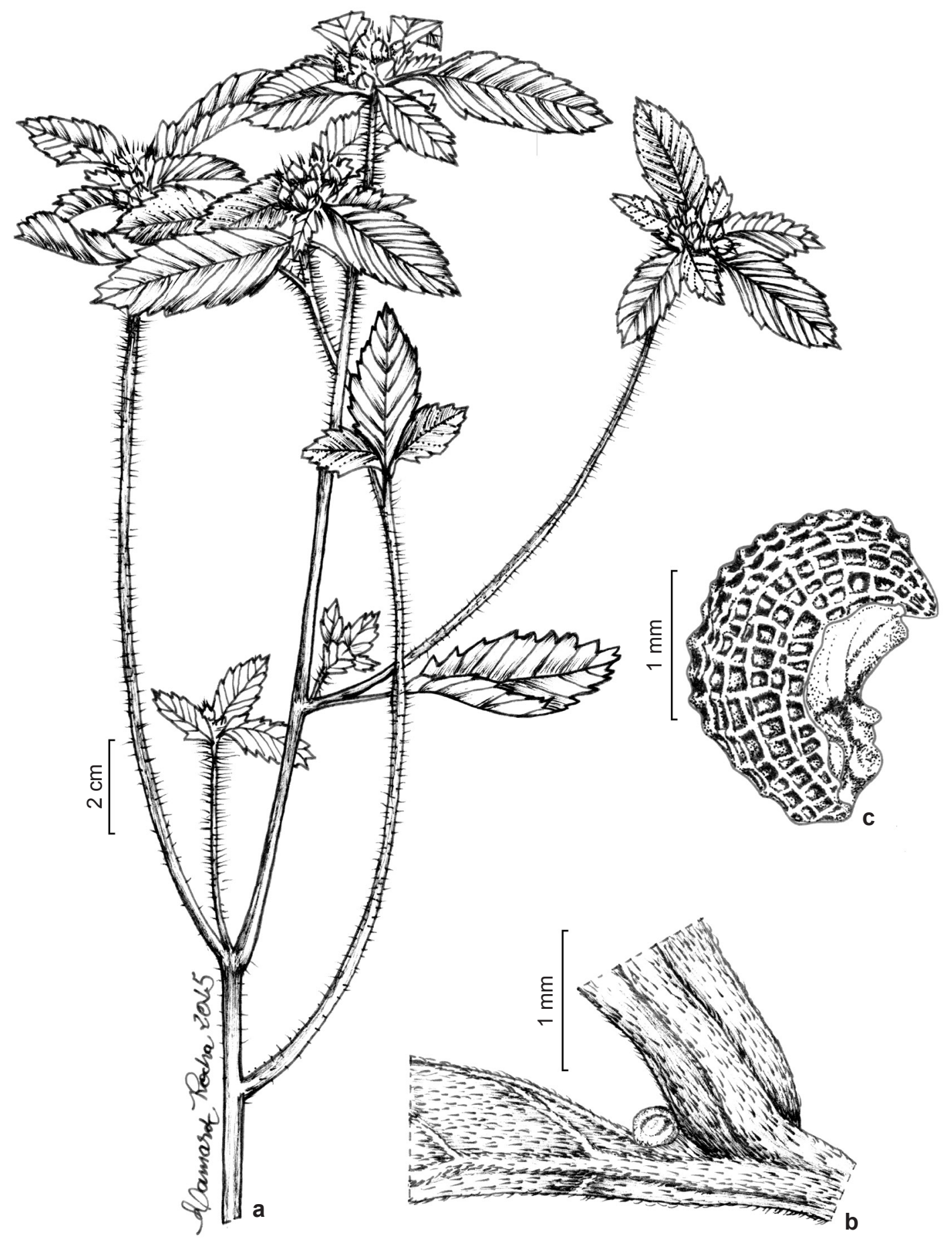

Figura 3 -a,c. Turnera pumilea - a. ramo reprodutivo (Rocha 383); b. T. subulata-flor epifila, evidenciando nectário extrafloral (Silva 1316); c. semente (Rocha 383).

Figure 3 - a,c. Turnera pumilea - a. reproductive branch (Rocha 383); b. T. subulata - epiphyll flower, showing extra-floral nectary (Silva 1316); c. seed (Rocha 383). 
Material selecionado: ALAGOAS: Olho d'Água do Casado, Fazenda Picos, 22.XI.1999, fl. e fr., R.A. Silva \& D. Moura 1316 (PEUFR, RB, UFP); Piranhas, 14.X.1999, fl. e fr., R.A. Silva 1136 (PEUFR). SERGIPE: Canindé do São Francisco, Fazenda Poço Verde, 21.VIII.2000, fl. e fr., R.A. Silva et al. 1717 (RB); Pão de Açúcar, 22.VI.2002, fl. e fr., R.P. Lyra-Lemos et al. 6853 (HUEFS); Poço Redondo, Monumento Natural Grota do Angico, 22.IX.2009, fl. e fr., J.E. Nascimento-Junior \& T. Dantas 619 (ASE, CTES); Porto da Folha, povoado Lagoa Grande, Fazenda São Pedro, 19.IV.2011, fl. e fr., D.G. Oliveira et al. 152 (ASE).

Ruderal, ocorre principalmente na América do Sul, mas também pode ser encontrada na Ásia (Arbo 2005). No Brasil, é amplamente distribuída, ocorrendo em todas as regiões (BFG 2015). Na Região de Xingó, foi encontrada na caatinga, crescendo sobre substratos argilosos e arenosos; floresce e frutifica durante o ano todo.

Pode ser reconhecida pelas flores heterostilas com corola creme de base castanho-escura. Assemelha-se a Turnera scabra Millsp., sendo o material seco de difícil separação, pode ser diferenciada principalmente pela corola amarela com base amarelo-escura.

\section{Agradecimentos}

Aos curadores dos herbários citados, por proporcionarem acesso às coleções e ao suporte para os estudos morfológicos. À CAPES (Coordenadoria de Aperfeiçoamento de Pessoal de Nível Superior), a bolsa de Doutorado concedida a L.R. Aos revisores e editores, as importantes sugestões para a melhoria do manuscrito. A Naron Silva Tanzillo, a confecção do mapa. J.I.M. Melo agradece ao CNPq (Conselho Nacional de Desenvolvimento Científico e Tecnológico), a bolsa de Produtividade em Pesquisa (PQ - Proc. n. 303867/2015-9).

\section{Referências}

Agra, M.F.; Kiriaki, N.S.; Costa-Silva, R. \& Gomes-Costa, G. 2009. Turneraceae. In: Alves, M.; Araújo, M.F.; Maciel, J.R. \& Martins, S. (eds.). Flora de Mirandiba. Associação Plantas do Nordeste, Recife. Pp. 344-347.

APG IV (Angiosperm Phylogeny Group). 2016. An update of the Angiosperm Phylogeny Group classification for the orders and families of flowering plants: APG IV. Botanical Journal of the Linnean Society 181: 1-20.

Arbo, M.M. 1995a. Turneraceae. Parte I. Piriqueta. Flora Neotropica 67: 1-156.

Arbo, M.M. 1995b. Turneraceae. In: Stannard, B.L. (ed.). Flora of the Pico das Almas, Bahia-Brasil. Royal Botanic Gardens, Kew. Pp. 615-619.

Arbo, M.M. 1997. Estudios sistemáticos en Turnera (Turneraceae). I. Series Salicifoliae y Stenodictyae. Bonplandia 9: 151-208.
Arbo, M.M. 2000. Estudios sistemáticos en Turnera (Turneraceae). II. Series Annulares, Capitatae, Microphyllae y Papilliferae. Bonplandia 10: 1-82.

Arbo, M.M. 2005. Estudios sistemáticos en Turnera (Turneraceae). III. Series Anomalae y Turnera. Bonplandia 14: 115-318.

Arbo, M.M. 2006. Turneraceae. In: Barbosa, M.R.V.; Sothers, C.; Mayo, S.; Gamarra-Rojas, C.F.L. \& Mesquita, A.C. (eds.). Checklist das plantas do nordeste Brasileiro: Angiospermas e Gymnospermas. Ministério da Ciência e Tecnologia, Brasília. Pp. 150-151.

Arbo, M.M. 2007. Turneraceae. In: Kubitzki, K.; Rhower, J.B. \& Bittrich, V. (eds.). The families and genera vascular plants. Vol. 9. Springer, Heidelberg. Pp. 458-466.

Arbo, M.M. 2008. Estudios sistemáticos en Turnera (Turneraceae). IV. Series Leiocarpae, Conciliatae y Sessilifoliae. Bonplandia 17: 107-334.

Arbo, M.M. 2013. Turneraceae. In: Prata, A.P.N.; Amaral, M.C.E.; Farias, M.C.V. \& Alves, M.V. (orgs.). Flora de Sergipe. Vol. 1. Gráfica e Editora Triunfo, Aracajú. Pp. 533-549.

Arbo, M.M. 2015. Turnera confertiflora (Turneraceae), especie nueva del "cerrado" de Tocantins (Brasil). Bonplandia 21: 23-26.

Arbo, M.M. \& Mazza, S.M. 2011. The major diversity centre for Neotropical Turneraceae. Systematics and Biodiversity 9: 203-210.

BFG. 2015. Growing knowledge: an overview of seed plant diversity in Brazil. Rodriguésia 66: 1085-1113.

CRIA. 2005. Geoloc. Disponível em $<$ http://splink.cria.org. br/geoloc $>$. Acesso em 10 dezembro 2015.

Cronquist, A. 1981. An integrated system of classification of flowering plants. The New York Botanical Garden, Columbia University Press, New York. 1261p.

González,A.M. \& Arbo, M.M. 2004. Trichome complement of Turnera and Piriqueta (Turneraceae). Botanical Journal of the Linnean Society 144: 85-97.

Harris, J.G. \& Harris, M.W. 1994. Plant identification terminology: an illustrated glossary. Spring Lake Publishing, Utah. 216p.

IBGE. 2012. Manual técnico da vegetação brasileira. $2^{\mathrm{a}}$ ed. Disponível em <ftp://geoftp.ibge.gov.br/ documentos/recursos_naturais/manuais_tecnicos/ manual_tecnico_vegetacao_brasileira.pdf $>$. Acesso em 10 dezembro 2014.

Machado-Filho, H.O.; Melo, J.I.M. \& Sales, M.F.S. 2012. Flora da Região de Xingó, Alagoas-Sergipe: Portulacaceae sensu lato. Biotemas 25: 103-108.

Melo, J.I.M.; Silva, M.J. \& Sales, M.F. 2009a. Flora da Região de Xingó, Alagoas e Sergipe: Onagraceae Juss. Sitientibus Série Ciências Biológicas 9: 106-109.

Melo, J.I.M.; Silva, M.J. \& Sales, M.F. 2009b. Flora da Região de Xingó, Alagoas e Sergipe: Loasaceae Juss. Sitientibus Série Ciências Biológicas 9: 110-113.

Payne, W.W. 1978. A glossary of plant hair terminology. Brittonia 30: 239-255. 
Radford, A.E.; Dickison, W.C.; Massey, J.R. \& Bell, C.R. 1974. Vascular plant systematics. Harper \& Row Publishers, New York. 891p.

Rocha, L. \& Moreira, H.J.C. 2014. Turneraceae of Bahia, Brazil. Chicago: The Field Museum (Rapid Color Guide). Disponível em <http://fm2.fieldmuseum.org/plantguides/ guideimages.asp?ID=649>. Acesso em 10 dezembro 2015.

Rocha, L.N.G.; Melo, J.I.M. \& Camacho, R.G.V. 2012. Flora do Rio Grande do Norte, Brasil: Turneraceae Kunth ex DC. Rodriguésia 63: 1085-1099.

Santos, J.S.; Melo, J.I.M.; Abreu, M.C. \& Sales, M.F.S. 2009. Verbenaceae sensu stricto na Região de Xingó: Alagoas e Sergipe, Brasil. Rodriguésia 60: 985-998.
Silva, M.J.; Melo, J.I.M. \& Sales, M.F.S. 2010. Flora da Região de Xingó, Alagoas e Sergipe: Acanthaceae A. Juss. Revista Caatinga 23: 59-67.

Souza, I.; Coutinho, K.; Melo, E. \& Arbo, M.M. 2013. Turneraceae. In: França, F.; Melo, E.; Souza, I. \& Pugliesi, L. (orgs.). Flora do Morro do Chapéu. Vol. 1. Print Mídia, Feira de Santana. Pp. 221-235. Thulin, M.; Razafimandimbison, S.G.; Chafe, P.; Heidari, N.; Kool, A. \& Shore, J.S. 2012. Phylogeny of the Turneraceae clade (Passifloraceae s.l.): TransAtlantic disjunctions and two new genera in Africa. Taxon 61: 308-323.

Tokuoka, T. 2012. Molecular phylogenetic analysis of Passifloraceae sensu lato (Malpighiales) based on plastid and nuclear DNA sequences. Journal of Plant Research 125: 489-497. 